\title{
Role of Higher Authorities (HED and HOIs) in Uplifting of Female's Sports at College
}

\author{
Level \\ * Afshan Jabeen, PhD Scholar \\ ** Dr. Syed Zia-ul-Islam, Lecturer \\ *** Mohammad Asghar Khan, PhD Scholar
}

\begin{abstract}
This study was designed to investigate the Higher Authorities (HED \& HOIs) role with reference to the promotion of sport among female students at college level Punjab, Pakistan. The HOIs and PETs of the Government girls' colleges in the province of Punjab was treated as population. Two type of self-develop questionnaires was used for data collection. One for HOIs and $2^{\text {nd }}$ for Physical Education Teachers (PETs). The HOIs provided data about the provision of financial aid and professional development programs) by HED and PETs provided the information regarding the role of HOIs in providing basic sports facilities to the players. The cluster sample random sampling technique was used for the selection of representative sample size from the whole population. The total 160 sample was selected in which 80 were HOIs and 80 were PETs. Chi-Square and One sample t-test were applied as statistical tool to analyzed the collected data. after the application of analyses, it was pointed out that Higher Education Department (HED) provide enough financial aid to Girls Degree colleges for female sports promotion. However, with reference to the role of HOIs, it was found ineffective and unsatisfactory in connection with providing of basic facilities ( sports equipment, coaching,nutritional support, psychological training, conducting of sports \& intramural classes etc) to students.
\end{abstract}

Keywords: Higher Authorities, HOI, HED, Female, Sports.

Introduction

Sports play a significant role in human life because sports participation has always been optimistic as friendly and get together the engagement of humans in daily life. Sport and recreational activities have the energy/potential to fulfill three main objectives that are psychological development, physical fitness, and attainment of motor skills (Cote \& Fraser, 2007). Gerber at el. (2012) described that participation in sport and physical activities has also shown optimistic and significant effects on mental, physical, and emotional health, and in reducing the stress of both genders. In this regard, the head of any college has a vital role in the progress of academic and sports activities. The role of principals as well as teachers is of paramount significance with reference to the sports promotion and overall success and prosperity of the institution. (McNeill, Sproule, \& Horton, 2003). In another study conducted by Flintoff (2003) identified that Sports development and college's repute both depends upon the deep interest and active involvement of HOIs, lecturers (PE) and other faculty. Likewise, for the prompt accomplishment of the sports goals and it's development, principals have to play a great responsibility to organize the sports events and to facilitate the players and teachers (Camiré, 2014). The aforementioned virtues are important for the HOIs for discharging their duties in regard of sports development effectively.

In addition to Nakpodia, (2006) described that the chief role of an administrator in every institutional setting lies in the effective and efficient utilization of all resources(human and material) within an integrated setting so that the stipulated goals can be obtained within the fixed time (). Similarly, Intramural sports require adequate funding as they are wide programs of sports and recreational activities organized within the institution. Obtaining predetermined sports goals in college students lie in the capability of the administrators of sports to utilize financial resources

* Department of Sports Sciences \& Physical Education, Gomal University D. I. Khan (KPK) Pakistan. Email: ajmalik54@gmail.com

** Department of Sports Sciences \& Physical Education, Gomal University D. I. Khan (KPK) Pakistan.

*** Department of Sports Sciences \& Physical Education, Gomal University D. I. Khan (KPK) Pakistan. Email: asgharkhan.bannu@gmail.com 
properly (Edenedo et al., 2014). Omolawon and Adisa (2009) espoused that as intramural sports is playing a lofty and beneficial role in youth development, the aims are threatened with barriers bothering on proper availability and utilization of fiscal resources. It is very important to note that an player who shows' in an inter-house sports competition should be provided some type of incentive or remuneration for excel performance, efforts and support towards the successful hosting of sports meets.

On the other hand, low level of awareness, time period, home restrictions, and lacking of financial resources and fellows, are found as the negative recreational factors about females' sport promotion (Hoden, 2010; Kara \& Demirci, 2010). Similarly, another research study also found that lack of basic facilities, fear of assault, gender, race, and high entry fees are the main factors that influence the sports development and other physical activities of different communities (Shores et al., 2007). It was observed that sports programme organization in college sector has endured various setbacks owing to issues created with improper budgeting and planing of financial resources at different women colleges of Punjab. So the current study aimed to explore the role of the H.E.D. and college HOIs regarding the females' sports promotion at the college level, in Punjab, Pakistan.

\section{Literature Review}

The following section dealt with the related literature of previous studies. It provides a theoretical base and sufficient knowledge required for the problem to continue (Ostrom, 2009). In this regard, Sports are consider as essential parts of the complete process of academics that impart to the human development and intellectual growth of the students. It imparts to the physical, social, cognitive and emotional development of pupils that cannot be neglected. In the same way, Shah (2016) elaborated that Sports consume the extra potential to make the man much strong, powerful, strengthen and active, his/her muscles and bones and tone the entire body in the right way and. It enhances the stamina, flexibility, endurance, agility of the person and all these things changes into complete physical fitness.

In addition to Sports activities, require some type of resources (staff, equipment, space, \& finance) for it's smooth functioning and propagation (Chelladurai, 2014). The author further explained that means is an aid which is required to support, to draw and to obtain something. it is necessary to provide all the needed facilities for players in sport area. Thus, Jabeen and Khan (2016) described that for the uplifting of woman's college sports events, the H.E.D. has a significant part to play such as pay proper concentration to sports, provide sports grants and arrange seminars, training, and workshop concerning sports and other recreational activities among the public colleges in the province of Punjab. Sarwer et al. (2010) signified that the government has to play a chief role in sports development at the college level. Another study by Wilensky (2015) indicated that great zeal and zest and optimistic staff cooperation, good communication among the higher authorities, and provisional administration are the basic needs for sports promotion.

Along with, the college principals have to play a pivotal role to utilize allocated grants for sports purpose and provide all basic facilities to players for sports events. Similarly, a research study by Merkel (2013) concluded that a positive behavior of HOIs towards recreational activities and sports and the provision of financial resources are some basic needs for the sports development. On the other hand, the non-availability of basic resources such as lack of playgrounds, sports equipment, transport faculty, and low interest of HOIs and staff are some hindrances in the promotion of the sport (Moscheny et al., 2011). Another study supported that lack of financial support, sports equipment and low level of interest of heads, staff, pupils and their parents are some basic factors that influence sport participation and promotion (Sarwar et al., 2010). Sports and games in the Government colleges in different districts of Punjab have been on the significant decline especially in female folk.In the present scenario, various hurdles are facing in the participation of females in sport events in which the main factors are lack of financial resources and poor or low interest of heads of the institution about activities of sports.

\section{Research Questions}

The study was based on the following research questions

- Whether the role of Higher Education Department (H.E.D) in the promotion of Sports at female colleges in Punjab, Pakistan is up to the mark? 
- Whether the role of Head of the institutions (H.O.Is) in the promotion of Sports at female colleges in Punjab, Pakistan is positive or appreciable?

- Whether the operating procedures adopted for the expenditure of fund and grant with reference to sports in the female colleges of Punjab in Pakistan is standardized?

\section{Research Methodology}

The study was quantitative in nature. Keeping in view the nature of the study survey method was adopt for the smooth conduction of the study. All the Head of the institutions (HOIs) and Physical Education Teachers (PETs) working in government girl's degree colleges of Punjab, Pakistan were selected as Population. There were total 315 Government girl's degree colleges in all the 36 districts Punjab. In first stage cluster sample random sampling technique was followed for the selection of district considered as a cluster, and in second stage, proportionate sampling technique was applied for the selection of girl's Degree colleges from each selected cluster. To confirm the size of sample Dr. Khan formula was used (Khan and Khan ,2015) and selected 10 districts as clusters (25\% out of 36 districts) and 80 girl's degree colleges, (25\% out of 315 college) were taken as sample. The 80 head of institutions, and 80 physical education teachers were taken as a sample from all the selected colleges. In this way the total 160 sample was selected form the targeted population.

\section{Table \# 1:}

Sampling Description

\begin{tabular}{clcccc}
\hline S.NO & Districts' Name & Colleges & Principals & Lecturers(PE) & Total \\
\hline $\mathbf{1 .}$ & Sargodha & 08 & 08 & 08 & 16 \\
$\mathbf{2 .}$ & Lahore & 08 & 08 & 08 & 16 \\
$\mathbf{3 .}$ & Rawalpindi & 08 & 08 & 08 & 16 \\
$\mathbf{4 .}$ & Layyah & 08 & 08 & 08 & 16 \\
$\mathbf{5 .}$ & Faisalabad & 08 & 08 & 08 & 16 \\
$\mathbf{6 .}$ & Bahkkar & 08 & 08 & 08 & 16 \\
$\mathbf{7 .}$ & D.G. Khan & 08 & 08 & 08 & 16 \\
$\mathbf{8 .}$ & Gujranwala & 08 & 08 & 08 & 16 \\
$\mathbf{9 .}$ & Multan & 08 & 08 & 08 & 16 \\
$\mathbf{1 0}$ & Mianwali & 08 & 08 & 08 & 16 \\
& Total & $\mathbf{8 0}$ & $\mathbf{8 0}$ & $\mathbf{8 0}$ & $\mathbf{1 6 0}$ \\
\hline
\end{tabular}

Furthermore, two self-administered Likert type questionnaires were designed for data collection. One for HOIs and the second was for PETs. As the present study dealt with two different variables such as predictor (the Higher authorities role) and criterion (females sports development), therefore the researchers collected information from HOIs for determining the role of HED in regard of allocation of grants and professional development programs ( sports training and coaching) and from PETs to determine the role of HOIs in providing basic sports facilities ( sports equipment, coaching,nutritional support, psychological training, conducting of sports \& intramural classes etc.). The process of validity and reliability of the questionnaire was made accordingly. The questionnaire was personally distributed among the selected sample and received back the fill questionnaire after given time. With the help of SPSS, version 24 , the gathered data was analyzed and chi-square and one sample t-test were applied.

\section{Results and Discussion}

\section{Table \# 2:}

One sampling t-test showing provision of financial grant by (HED) to Government Girls College for the Promotion sports.

\begin{tabular}{ccccccc}
\hline \multicolumn{2}{c}{ Testing variable } & N & Mean & Std. Deviation & Std. Error Mean \\
\hline \multicolumn{2}{c}{ H.E.D } & 80 & 1.6786 & .65042 & .07272 \\
$\begin{array}{c}\text { Testing } \\
\text { variable }\end{array}$ & T & Df & Sig. (2-tailed) & $\begin{array}{c}\text { Mean } \\
\text { Difference }\end{array}$ & $\begin{array}{c}\text { 95\% Confidence } \\
\text { Lower }\end{array}$ \\
H.E.D & 2.456 & 79 & .016 & .17863 & .0339 & Upper \\
\hline
\end{tabular}

Test Value $=1.5$

The above table 2 indicates testing value 1.5 , The P-value $=.016$ which is less than the alpha level 0.05 which shows that the role of HED Punjab in respect of allocation grants to Governments girl's degree colleges was sufficient and satisfactory. 
Table \# 3:

One sample t-test showing the role in HOIs in their respective colleges regarding utilization of provided fund for females' sports.

\begin{tabular}{|c|c|c|c|c|c|}
\hline Testing variables & & $\mathbf{N}$ & Mean & Std. Deviation & Std. Error Mean \\
\hline Role of HOIs & & 80 & 1.23 & .342042 & .03272 \\
\hline \multirow{3}{*}{$\begin{array}{l}\text { Testing variable } \\
\text { Role of HOIs }\end{array}$} & \multirow{3}{*}{ T } & \multirow{3}{*}{$\begin{array}{l}\text { Df } \\
79\end{array}$} & \multirow{3}{*}{$\begin{array}{c}\text { Sig. (2-tailed) } \\
.056\end{array}$} & \multirow{3}{*}{$\begin{array}{c}\text { Mean } \\
\text { Difference } \\
.134563\end{array}$} & 95\% Confidence \\
\hline & & & & & Upper \\
\hline & & & & & .03422 \\
\hline
\end{tabular}

Test Value $=1.5$

Table 3 depicts that testing value 1.5. The $\mathrm{P}$-value $=.056$ which is greater than the alpha level 0.05. The data reveals that the role of HIOs in respect of utilization of sports funds in their colleges was not satisfactory with reference to the promotion of sports among female students at college level.

Table \# 4:

Chi-square Test showing the standard of operating procedure for expenditure of funds and grants in regard to promote females' sports at degree college level.

\begin{tabular}{|c|c|c|c|c|c|}
\hline S. No & Statements & Yes & No & $X^{2}$ & P-value \\
\hline 1. & Sports funds and grants are completely utilized & $11 \%$ & $89 \%$ & \multirow{7}{*}{0.97} & \multirow{7}{*}{0.35} \\
\hline 2. & The funds utilization system is clear and transparent & $14 \%$ & $86 \%$ & & \\
\hline 3. & $\begin{array}{l}\text { There is a proper/specific committee to check the } \\
\text { sports expenditures }\end{array}$ & $33 \%$ & $67 \%$ & & \\
\hline & $\begin{array}{l}\text { There is a check and balance system for the } \\
\text { utilization of sport grants and other funds }\end{array}$ & $22 \%$ & $78 \%$ & & \\
\hline 5. & $\begin{array}{l}\text { Regular audit procedure for sports grants is being } \\
\text { properly done annually }\end{array}$ & $43 \%$ & $57 \%$ & & \\
\hline & $\begin{array}{l}\text { The operating procedure is authentically and } \\
\text { accordingly apply for funds utilization of sports }\end{array}$ & $12 \%$ & $88 \%$ & & \\
\hline & Total & $22.5 \%$ & $77.5 \%$ & & \\
\hline
\end{tabular}

The table 4 shows the percentage of respondents $\mathrm{No}=77.17 \%$ and Yes $=22.83 \%$, the $\mathrm{x} 2$ value shows $0.97, \mathrm{P}=0.35$ which is greater than the alpha level 0.01 . It indicated that the operating procedure is not properly working for the expenditure of sport funds and grants with reference to females' sports in degree colleges of Punjab, Pakistan.

\section{Discussions}

This study was designed to investigate the Higher Authorities (HED \& HOIs) role with reference to the promotion of sport among female students at college level Punjab, Pakistan. The current research found that role of HOIs in the promotion of sports was not up to the mark. They do not pay due attention to sports activities. Because PETs were of the opinion that inappropriate utilization of sports funds by HOIs is one of the main factor of non participation of students in girl's degree colleges of Punjab. Sarwar et al., (2010) supported the current study finding that lack of HOIs' interest is basic factor that influence the sport participation and promotion. (Cuypers at el. (2012) indicated discontentment among the participants concerning the role of HOIs in college sports promotion.

This study found that many of the participants had shown contentment about the H.E.D role regarding the uplifting of females' sports at college level, Punjab, Pakistan. The provision of regular grants for sports, proper concentration to female sports personnel, and off and on visits by sports and higher authorities in respective to females colleges were the basic reasons leading to the significant role of H.E.D in the uplifting and promoting of sports activities. Zhou, (2010) indicated that the higher authorities are accountable for the downfall and promotion of sports and games. Likewise, Arslan, (2010) revealed that if the sports and higher authorities are devoted, honest and having a broad vision regarding the sports, they will get success to promote sport among their institutions. Wilensky, (2015) also signified that great zeal and optimistic cooperation among the staff, and higher authorities are essential for sports promotion Furthermore, the present research also indicated that the operating procedure is not appropriately functioning to promote sports culture among females in girl's degree colleges of Punjab, Pakistan. Moschny et al., (2011) and Riess, (2012) claimed that positive attitude and appropriately functioning of HOIs towards sports activities are the basic requirements for the uplifting of sports. 


\section{Conclusion}

On the bases of analyses, it is concluded that there was dissatisfaction among the respondents (PETs) regarding the role of HOIs in the uplifting of females' sports at girl's degree college level. The respondents were of the opinion that HOIs show poor interest with reference to sports and available funds and grants are being constantly utilized for other purposes than sports. It was also observed that HED provides a sufficient grant and and professional development programs ( sports training and coaching) opportunities every year for female sports to girl's degree colleges as perceived by the HOIs. But unluckily, the HOIs role found unsatisfactory to properly utilized the sports fund in girl's degree colleges. Lack of interest, motivation, lack of sports equipment and other facilities were identified as a negative factor in the way of female sport promotion at government girl's degree colleges Punjab, Pakistan.

\section{Recommendations:}

On the basis of findings of the study, it is recommended:

- The Higher Education Department should make some strong and valid policies to ensure the process of utilization of grants and funds regarding sports in educational institutions.

- Different workshops, seminars, and training programs should be arrange by the HED for

References: professional development.

Arslan, (2010). Research information and recommendations to improve sports facilities in university. Thesis report submitted to the Superior University Lahore.

Camiré, M. (2014). Youth development in North American high school sport: Review and recommendations. Quest, 66(4), 495-511.

Chelladurai, P. (2014). Managing organizations for sport and physical activity: A systems perspective. Taylor \& Francis.

Côté, J., \& Fraser-Thomas, J. (2007). Youth involvement in sport. Sport psychology: A Canadian perspective, 270-298.

Cuypers, K., Krokstad, S., Holmen, T. L., Knudtsen, M. S., Bygren, L. O., \& Holmen, J. (2012). Patterns of receptive and creative cultural activities and their association with perceived health, anxiety, depression and satisfaction with life among adults: the HUNT study, Norway. J Epidemiol Community Health, 66(8), 698-703.

Edenedo, E. E., Akarah, E., \& Tayire, F. O. (2014). Administrators' Finance Utilization as Predictor of Intramural Sports Development in Government Secondary Schools in Delta Central Senatorial District. Academic Journal of Interdisciplinary Studies, 3(6), 145.

Flintoff, A. (2003). The school sport co-ordinator programme: changing the role of the physical education teacher?. Sport, education and society, 8(2), 231-250.

Gerber, M., Kalak, N., Lemola, S., Clough, P. J., Pühse, U., Elliot, C., ... \& Brand, S. (2012). Adolescents' exercise and physical activity are associated with mental toughness. Mental health and physical activity, 5(1), 35-42.

Hoden, M. (2010) Constraints to Participation in an Outdoor Orientation Program. Unpublished Master thesis, West Virginia University.

Zhou, H. (2010). Research on relationship between College Sports Facilities and Mass Sports. In The Conference on Web Based Business Management (pp. 425-428).

Jabeen, A., \& Khan, S. (2016). "Study Regarding Allocation And Utilization Of Sport Funds For The Uplift And Promotion Of Sports Among Female Colleges In Punjab". Gomal University d.i.Khan, KPK.

Kara, F. and Demirci, A. (2010) An Assessment of Outdoor Recreational Behaviors and Preferences of the Residents in Istanbul. Scientific Research and Essay, 5(1), 93-104.

Khan Salahuddin and Khan, M. (2015). Impact of Sports on academic achievement with spcial reference to Gomal University Dera Ismail Khan. Gomal University Journal of Research. Vol: 20, Pp-1555-163

McNeill, M., Sproule, J., \& Horton, P. (2003). The changing face of sport and physical education in post-colonial Singapore. Sport, Education and Society, 8(1), 35-56.

Merkel, D. L. (2013). Youth sport: positive and negative impact on young athletes. Open access journal of sports medicine, 4, 151. 
Moschney, E., et al. (2011). Barriers to Physical activity in older adults in Germany: A CrossSectional Study. International journal of Behavioral Nutrition and Physical Activity.

Nakpodia, A. (2006). Educational administration. Meaning, concept and theories of educational administration. Effurun: Jonokase

Omolawon, K. O., \& Adisa, O. (2009). Budget planning, allocation and implementation as indices for intramural sports programme among Osun State Owned Tertiary Institution. Nigeria Journal of Sports Management, 3, 24.

Ostrom, E. (2009). A general framework for analyzing sustainability of social-ecological systems. Science, 325(5939), 419-422.

Riess, S. A. (2012). Sport in industrial America, 1850-1920. John Wiley \& Sons.

Sarwar, M. Hussain, S., et al. (2010). Physical Education at secondary school level in Gujranwala. Pakistan. Asian Journal of Social Sciences. 6 (11).1-3.

Shah, D. (2016). Country report on decentralization in the education system of Pakistan: Policies and strategies. Islamabad: Academy of Educational Planning and Management,(Islamabad), Ministry of Education.

Shores, K. A., Scott, D., \& Floyd, M. F. (2007). Constraints to outdoor recreation: A multiple hierarchy stratification perspective. Leisure sciences, 29(3), 227-246.

Wilensky, H. L. (2015). Organizational intelligence: Knowledge and policy in government and industry (Vol. 19). Quid Pro Books. 